\title{
Prospeção de inibidores de serinoproteinases em folhas de leguminosas arbóreas da floresta Amazônica
}

\author{
Larissa Ramos CHEVREUIL ${ }^{1}$, José Francisco de Carvalho GONÇALVES², Flávia Camila SCHIMPL ${ }^{3}$, \\ Cristiane Santos do Carmo Ribeiro de SOUZA ${ }^{4}$, Luiz Augusto Gomes de SOUZA ${ }^{5}$, Silvana Cristina PANDO 6
}

\section{RESUMO}

Os inibidores de proteinases são proteínas extensivamente investigadas nos tecidos de estocagem, mas pouco prospectadas em outros tecidos vegetais. $\mathrm{O}$ objetivo deste estudo foi detectar a presença de inibidores de serinoproteinases em extratos foliares de quinze espécies de leguminosas arbóreas da Amazônia. As espécies estudadas foram: Caesalpinia echinata, C. ferrea, Cedrelinga cateniformis, Copaifera multijuga, Dinizia excelsa, Enterolobium contortisiliquum, E. maximum, E. schomburgkii, Leucaena leucocephala, Ormosia paraensis, Parkia multijuga, P. pendula, P. platycephala, Swartzia corrugata e S. polyphylla. Folhas foram coletadas, secas a $30^{\circ} \mathrm{C}$ durante $48 \mathrm{~h}$, trituradas e submetidas à extraçáo com $\mathrm{NaCl}(0,15 \mathrm{M}, 10 \% \mathrm{p} / \mathrm{v})$ resultando no extrato total. Ensaios foram executados para determinar a concentração de proteínas e detectar a atividade inibitória contra a tripsina e quimotripsina bovina. Os teores de proteínas bruta e solúvel nos extratos foliares variaram de 7,9 a $31,2 \%$ e 1,3 a $14,8 \%$, respectivamente. A atividade inibitória sobre a tripsina e quimotripsina foi observada em todos os extratos foliares. Contudo, nos extratos de E. maximum, L. leucocephala, P. pendula, S. corrugata e $S$. polyphylla a inibiçáo foi maior sobre a tripsina, enquanto o extrato de $P$. multijuga foi mais efetivo contra a quimotripsina. Nós concluímos que nos extratos foliares de leguminosas arbóreas têm inibidores de serinoproteinases e exibem potencial aplicaçôes biotecnológicas.

PALAVRAS-CHAVE: Espécies arbóreas, proteínas, quimotripsina, Tripsina.

\section{Prospecting serine proteinase inhibitors in leaves from leguminous trees of the Amazon forest}

\section{ABSTRACT}

The proteinase inhibitors are proteins extensively investigated in tissue storage, but few prospected in other plant tissues. The aim of this study was to detect the presence of serine proteinase inhibitors in leaf extracts from fifteen species of leguminous trees of the Amazon forest. The species studied were Caesalpinia echinata, C. ferrea, Cedrelinga cateniformis, Copaifera multijuga, Dinizia excelsa, Enterolobium contortisiliquum, E. maximum, E. schomburgkii, Leucaena leucocephala, Ormosia paraensis, Parkia multijuga, P. pendula, P. platycephala, Swartzia corrugata and S. polyphylla. Leaves were collected, dried at $30^{\circ} \mathrm{C}$ for $48 \mathrm{~h}$, crushed and subjected to extraction with $\mathrm{NaCl}(0.15 \mathrm{M}, 10 \% \mathrm{w} / \mathrm{v})$, resulting in the total extract. Tests were performed to determine the concentration of proteins and to detect of inhibitory activity against bovine trypsin and chymotrypsin. The content of crude and soluble protein in leaf extracts varied from 7.9 to $31.2 \%$ and 1.3 to $14.8 \%$, respectively. The inhibitory activity on trypsin and chymotrypsin was observed in all leaf extracts. However, in extracts of E. maximum, L. leucocephala, P. pendula, S. corrugata and S. polyphylla, the inhibition was greater on trypsin, while extract of P. multijuga was more effective against chymotrypsin. We conclude that leaf extracts of leguminous trees have serine proteinase inhibitors and show potential biotecnological applications.

KEYWORDS: Chymotrypsin, proteins, tree species, trypsin.

\footnotetext{
1 Instituto Nacional de Pesquisas da Amazonas. Iarissachevreuil@gmail.com

2 Instituto Nacional de Pesquisas da Amazonas. jfc@inpa.gov.br

3 Instituto Nacional de Pesquisas da Amazonas. fla_schimpl@hotmail.com

${ }^{4}$ Universidade Federal do Amazonas. souza_santos_cristiane@hotmail.com

${ }^{5}$ Inatituto Nacional de Pesquisas do Amazonas -CPCA. souzalag@inpa.gov.br

${ }^{6}$ Universidade Federal do Amazonas. scpando@ufam.edu.br
} 


\section{INTRODUÇÃO}

Do ponto de vista da representatividade botânica, a família Fabaceae compreende a terceira maior família de plantas juntamente com a Orchidaceae e Asteraceae, com 727 gêneros e 19.325 espécies, as quais estáo presentes em diversos biomas espalhados pelo planeta (Silva e Souza 2002; Ferreira et al. 2004; Lewis et al. 2005).

No bioma amazônico, a diversidade em leguminosas arbóreas, em grande parte apresenta valor econômico, sendo espécies aproveitadas principalmente para a extração de madeira (Barbosa et al. 2006). Entretanto, sabe-se que a importância econômica das leguminosas é grande e muito diversificada, sendo as espécies desta família botânica usadas desde a alimentação humana e animal (fonte de aminoácidos e proteínas) até no enriquecimento de solos (fixação biológica de nitrogênio), além de serem fontes de outros compostos (não-nitrogenados) com aplicaçóes diretas nos processos de industrialização, como por exemplo, o óleo de copaíba, verniz copal, corantes, gomas naturais, taninos e substâncias para uso medicinal (Ferreira et al. 2004, Barbosa et al. 2006).

Nesse contexto, realizar investigaçóes bioquímicas nos extratos provenientes da madeira, casca, sementes e das folhas das leguminosas arbóreas, representa iniciativa científica muito relevante para a caracterização e isolamento de metabólitos com atividade biológica e descoberta de novos materiais para a indústria de cosméticos, farmacêutica, alimentícia e madeireira (Barbosa et al. 2006).

Nos extratos de plantas é possível encontrar grande diversidade de biomoléculas. Dentre os metabólitos presentes nestes extratos e com possíveis aplicaçôes industriais, encontra-se a classe protéica dos inibidores de proteinases, que são proteínas capazes de formar complexos com enzimas proteolíticas, bloqueando reversível ou irreversivelmente a sua atividade catalítica (Richardson 1991; De Leo et al. 2002; Chye et al. 2006).

Estas proteínas são amplamente distribuídas na natureza e, nas plantas, relacionam-se com a estocagem de proteínas e/ou mecanismos de defesa vegetal (Haq et al. 2004; Macedo et al. 2007; Torres-Castillo et al. 2009). Ademais, os inibidores de proteinases são classificados de acordo com a classe de enzima inibida, podendo, então, serem inibidores de serino, cisteíno, aspártico e metaloproteinases (Richardson 1991; Haq et al. 2004; Ramos et al. 2008).

Os inibidores de serinoproteinases são os mais bem caracterizados e estão subdividos em famílias de acordo com a homologia da estrutura primária, a massa molecular, o conteúdo de cisteína e a localização do sítio reativo, destacando-se as famílias Kunitz e Bowman-Birk (Richardson 1991; Mosolov e Valueva 2005; Bhattacharyya et al. 2006). Adicionalmente, esses inibidores podem estar presentes em diferentes tecidos da planta, como nos de reserva (sementes e tubérculos), vegetativos (folhas) e reprodutivos (flores e frutos) (Xavier-Filho 1992; Gomes et al. 2005).

Apesar de os inibidores de proteinases serem encontrados em altas concentraçóes nos tecidos de estocagens de espécies leguminosas, poucos estudos tem sido realizados em tecidos foliares (Brzin et al. 1998; Vanderjagt et al. 2000; McManus et al. 2005). Assim, considerando que as folhas são em área superficial, o órgão mais exposto e, por conseguinte, mais susceptíveis ao ataque de pragas e patógenos, nós investigamos a hipótese de que folhas de leguminosas arbóreas expressam diferencialmente inibidores de tripsina e quimotripsina bovina visando contribuir para o entendimento da interaçáo planta - patógeno e subsidiar estudos que possibilitem a aplicaçáo dessas moléculas sobre fungos, insetos e bactérias de interesse para as diferentes áreas da bioindústria.

\section{MATERIAL E MÉTODOS}

$\mathrm{O}$ estudo foi conduzido no Laboratório de Fisiologia e Bioquímica Vegetal (MCT-INPA) nos anos de 2008 e 2009, utilizando-se como material biológico, folhas coletadas de 15 leguminosas arbóreas, das quais 13 (treze) delas cultivadas no arboreto de leguminosas do Campus III do INPA (Caesalpinia echinata Lam., C. ferrea C. Mart., Cedrelinga cateniformis (Ducke) Ducke, Copaifera multijuga Hayne, Dinizia excelsa Ducke, Enterolobium contortisiliquum (Vel.) Morong, E. maximum Ducke, E. schomburgkii (Benth.) Benth., Leucaena leucocephala (Lam.) de Wit., Ormosia paraensis Ducke, Parkia multijuga Benth., Swartzia corrugata Benth. e S. polyphylla DC.), 1(uma) na Reserva Ducke (Parkia pendula (Willd.) Walp.) e outra na Estação Experimental de Fruticultura (Parkia platycephala Benth.), todas no município de Manaus, AM.

$\mathrm{O}$ arboreto de leguminosas $\left(03^{\circ} 08^{\prime} \mathrm{S}\right.$ a $\left.60^{\circ} 01^{\prime} \mathrm{W}\right)$ foi plantado em solo Latossolo Amarelo de textura argilosa, no ano de 1989, com o objetivo de obtenção de propágulos para estudos agrosilviculturais e para difusão do plantio de espécies pouco cultivadas. Muitos indivíduos plantados a partir desta data encontram-se atualmente com 20 anos de idade, desenvolvidos, e em fase adulta e de reproduçáo.

\section{MATERIAL VEGETAL}

Nas espécies selecionadas foram coletadas folhas maduras, completamente expandidas e em bom estado fitossanitário, livre de necrose ou clorose. Algumas informaçóes sobre o nome popular, subfamília e padrão de renovação foliar destas espécies são apresentadas na Tabela 1.

Para a definição do padrão de fenologia foliar foram consideradas espécies perenifólias, caducifólias e semicaducifólias, para aquelas que possuem folhas perenes, caducas ou perdem as folhas parcialmente, definidas para as árvores matrizes em estudo. 
Tabela 1 - Nome vulgar, subfamília e fenologia foliar de 15 (quinze) espécies de leguminosas arbóreas presentes na Amazônia Central*.

\begin{tabular}{lccc}
\hline Espécie (nome científico) & Nome vulgar & Subfamília & Fenologia da folha \\
\hline Caesalpinia echinata & Pau Brasil & Caesalpinioideae & perenifólia \\
Caesalpinia ferrea & Jucá & Caesalpinioideae & semicaducifólia \\
Cedrelinga cateniformis & Cedrorana & Mimosoideae & perenifólia \\
Copaifera multijuga & Copaíba & Caesalpinioideae & perenifólia \\
Dinizia excelsa & Angelim pedra & Mimosoideae & perenifólia \\
Enterolobium contortisiliquum & Timbaúva & Mimosoideae & caducifólia \\
Enterolobium maximum & Fava tamboril & Mimosoideae & semicaducifólia \\
Enterolobium schomburgkii & Orelha de negro & Mimosoideae & semicaducifólia \\
Leucaena leucocephala & Leucena & Mimosoideae & perenifólia \\
Ormosia paraensis & Tento & Faboideae & perenifólia \\
Parkia multijuga & Pinho Cuiabano & Mimosoideae & caducifólia \\
Parkia pendula & Visgueiro & Mimosoideae & caducifólia \\
Parkia platycephala & Fava bolota & Mimosoideae & semicaducifólia \\
Swartzia corrugata & Coração de negro & Faboideae & perenifólia \\
Swartzia polyphylla & Arabá & Faboideae & perenifólia \\
\hline
\end{tabular}

*Fonte: Herbário do Instituto Nacional de Pesquisas da Amazônia (MCT-INPA)

\section{DETERMINAÇÃO DE PROTEÍNA BRUTA}

A determinação de proteína bruta foi realizada pelo método de micro - Kjeldahl (Anderson e Ingram 1993), a partir da quantificação de nitrogênio total e sua conversão utilizando o fator 6,25 (FAO 1982; Ezeagu et al. 2002).

Após secagem das folhas em estufa a $65^{\circ} \mathrm{C}, 100 \mathrm{mg}$ do material pulverizado foi submetido à digestão, em um bloco digestor a $350^{\circ} \mathrm{C}$, contendo uma mistura de selenito de sódio $(0,25 \mathrm{~g})$, sulfato de cobre (11,25 g), sulfato de sódio $(47,5 \mathrm{~g})$, ácido salicílico $(1,25 \mathrm{~g})$ e ácido sulfúrico $(500 \mathrm{~mL})$. A digestão prosseguiu até o material apresentar coloração esverdeada. Posteriormente, as amostras foram resfriadas e submetidas à destilação, acrescentando-se água destilada $(20 \mathrm{~mL})$, hidróxido de sódio 40\% (15 mL) e, separadamente em béquer, a solução receptora contendo ácido bórico. Para a titulação utilizou-se soluçấo de ácido sulfúrico a $0,01 \mathrm{~N}$.

\section{OBTENÇÃO DOS EXTRATOS FOLIARES}

As folhas coletadas tiveram o pecíolo retirado e foram secas em estufa a $30^{\circ} \mathrm{C}$ durante $48 \mathrm{~h}$. Posteriormente, as lâminas foliares foram trituradas em moinho analítico (Ika-Werke/ M20) até a obtenção de material finamente pulverizado. O material pulverizado $(10 \mathrm{~g})$ foi homogeneizado em 100 $\mathrm{mL}$ de $\mathrm{NaCl} 0,15 \mathrm{M}(10 \% \mathrm{p} / \mathrm{v})$ sob leve agitaçáo durante duas horas à temperatura ambiente $\left(25^{\circ} \mathrm{C} \pm 3\right)$. A suspensão foi centrifugada a $5000 \mathrm{~g}$, durante 20 minutos, a $4^{\circ} \mathrm{C}$ e o sobrenadante, após diálise durante $48 \mathrm{~h}$ contra água destilada, foi liofilizado e utilizado nas etapas posteriores.

\section{DETERMINAÇÃO DE PROTEÍNAS TOTAIS}

A concentração relativa de proteínas dos extratos foliares foi estimada de acordo com o método descrito por Bradford (1976), utilizando a albumina sérica bovina (BSA) como padrão. Os extratos $(50 \mu \mathrm{L})$ foram incubados durante 5 minutos à temperatura ambiente $\left(25^{\circ} \mathrm{C} \pm 3\right) \operatorname{com} 2,5 \mathrm{~mL}$ do reagente de Bradford (Bioagency). A concentração de proteínas foi estimada por meio da leitura em espectrofotômetro a 595 nm (UV/ Visível Ultrospec 2100 pro, Armesham Biosciences).

\section{MEDIDA DA INIBIÇÃO DE TRIPSINA BOVINA}

A mistura de pré-incubação, para o volume final de 2 $\mathrm{mL}$, foi constituída de $250 \mu \mathrm{L}$ de tampão Tris/ $\mathrm{HCl} 0,05$

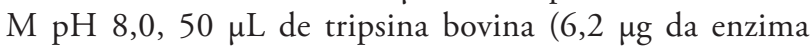
dissolvida em HCl $1 \mathrm{mM}$, Sigma) e $150 \mu \mathrm{L}$ dos extratos totais das diferentes espécies estudadas. A pré-incubação prosseguiu durante 10 minutos a $37^{\circ} \mathrm{C}$. Decorrido o tempo, $1 \mathrm{~mL}$ do substrato cromogênico DL-BAPNA 0,5 mM (DLbenzoil-arginina-paranitroanilida, Sigma) foi adicionado e a incubação prosseguiu durante 30 minutos, a $37^{\circ} \mathrm{C}$. A reação foi interrompida pela adição de ácido acético a 30\% (v/v) e a hidrólise do substrato pela enzima foi acompanhada espectrofotometricamente a $410 \mathrm{~nm}$ (Espectrofotômetro UV/ Visível Ultrospec 2100 pro, Armesham Biosciences) (Mello et al. 2001). O cálculo da atividade inibitória foi obtido a partir da determinação da atividade residual da tripsina no ensaio, de acordo com Erlanger et al. (1961). 


\section{MEDIDA DA INIBIÇÃO DE QUIMOTRIPSINA BOVINA}

A mistura de pré-incubação, para o volume final de $2 \mathrm{~mL}$, foi constituída de $500 \mu \mathrm{L}$ de tampão Tris/ $\mathrm{HCl}(\mathrm{pH} 8,0), 150$ $\mu \mathrm{L}$ de quimotripsina bovina $(0,2 \mathrm{mg}$ da enzima dissolvida em $\mathrm{HCl} 1 \mathrm{mM}$, Sigma) e $100 \mu \mathrm{L}$ dos extratos provenientes das diferentes etapas de isolamento. A pré-incubação prosseguiu durante 10 minutos a $37^{\circ} \mathrm{C}$. Decorrido o tempo descrito, $50 \mu \mathrm{L}$ do substrato cromogênico BTPNA 0,1 M (benzoil tirosina - paranitroanilida, Sigma) foi adicionado e, após 20 minutos de incubação, a reação foi interrompida pela adição de ácido acético a 30\% (v/v). A hidrólise do substrato pela enzima foi acompanhada espectrofotometricamente a 410 nm (Espectrofotômetro UV/ Visível Ultrospec 2100 pro, Armesham Biosciences) (Mello et al. 2001). O cálculo da atividade inibitória foi obtido a partir da determinaçáo da atividade residual da quimotripsina no ensaio, de acordo com Erlanger et al. (1961).

\section{RESULTADOS E DISCUSSÃO}

Os teores de proteínas bruta e solúveis nos extratos foliares das 15 espécies de leguminosas arbóreas estudadas variaram de 7,9 a $31,2 \%$ e 1,3 a $14,8 \%$, respectivamente, sendo o menor valor de proteína bruta encontrado para $D$. excelsa, enquanto o maior teor em C. multijuga (Tabela 2). No que diz respeito ao teor de proteínas solúveis, $D$. excelsa e $E$. schomburgkii apresentaram menor teor, ao passo que $P$. platycephalla exibiu maior conteúdo protéico.

O conteúdo de proteína bruta e solúvel em folhas de Fabaceae tem sido utilizado como um dos critérios de seleção de espécies com potencial forrageiro. Dentre as espécies estudadas a $L$. leucocephala é tradicionalmente empregada como planta forrageira (Hughes 1998) e apresentou o segundo maior teor de proteína bruta foliar.

Os resultados demonstraram alta variação de concentração protéica entre as espécies das três subfamílias de leguminosas, Caesalpinioideae, Mimosoideae e Faboideae, bem como entre as espécies pertencentes à mesma subfamília, podendo, estas variaçóes das concentraçôes protéicas, estarem associadas à capacidade da fixação biológica de nitrogênio, processo fisiológico e bioquímico realizado pelas plantas, em particular, espécies de leguminosas em associação com bactérias específicas.

Estudos realizados em extratos protéicos provenientes de sementes de E. schomburgkii, $P$. pendula e $P$. multijuga apresentaram concentraçâo protéica semelhantes ao encontrado nos extratos foliares dessas espécies (Chevreuil 2009). Adicionalmente, tanto nas sementes quanto nas folhas de E. schomburgkii os baixos teores de proteínas podem ser resultantes do tipo de extração (solução de $\mathrm{NaCl}$ ), visto que outros métodos de isolamento de proteínas, como por
Tabela 2 - Teor de proteínas bruta e solúveis (\%) em extratos foliares de 15 leguminosas arbóreas que crescem na Amazônia Central.

\begin{tabular}{lcc}
\hline \multirow{2}{*}{ Espécies } & \multicolumn{2}{c}{ Concentração de proteínas (\%) } \\
\cline { 2 - 3 } & Proteína Bruta* & Proteína solúvel** \\
\hline Caesalpinia echinata & $15,2 \pm 0,42$ & $6,1 \pm 0,16$ \\
Caesalpinia ferrea & $16,4 \pm 2,52$ & $4,1 \pm 0,45$ \\
Cedrelinga cateniformis & $12,3 \pm 1,79$ & $2,5 \pm 0,44$ \\
Copaifera multijuga & $31,2 \pm 0,63$ & $5,3 \pm 0,36$ \\
Dinizia excelsa & $7,9 \pm 0,31$ & $1,3 \pm 0,21$ \\
Enterolobium contortisiliquum & $18,7 \pm 0,10$ & $5,2 \pm 0,75$ \\
Enterolobium maximum & $13,0 \pm 0,04$ & $12,3 \pm 1,09$ \\
Enterolobium schomburgkii & $18,3 \pm 0,58$ & $1,8 \pm 0,56$ \\
Leucaena leucocephala & $25,3 \pm 0,60$ & $2,5 \pm 0,07$ \\
Ormosia paraensis & $11,5 \pm 0,43$ & $6,4 \pm 0,17$ \\
Parkia multijuga & $16,3 \pm 0,68$ & $6,3 \pm 0,19$ \\
Parkia pendula & $13,4 \pm 0,23$ & $9,7 \pm 1,46$ \\
Parkia platycephala & $12,4 \pm 0,16$ & $14,8 \pm 0,03$ \\
Swartzia corrugata & $19,0 \pm 0,43$ & $13,6 \pm 0,43$ \\
Swartzia polyphylla & $15,4 \pm 0,44$ & $5,3 \pm 0,84$ \\
\hline
\end{tabular}

*Estimada pelo método de Kiedahl.

**Estimada pelo método de Bradford.

( $n=45$, médias seguidas de desvios padrão)

exemplo a precipitação cetônica e por sulfato de amônio em diferentes saturaçôes, tem sido aplicados e proporcionam bom rendimento de inibidores de proteinases (Pando et al. 2001; Gomes et al. 2005; Bhattacharyya e Babu 2009).

O fato é que, a extração de proteínas das partes verdes das plantas, diferentemente da extração nas sementes, é mais difícil devido aos aspectos quantitativos destas biomoléculas nos tecidos verdes (cerca de 5\% da fitomassa verde), enquanto que nos tecidos de estocagens das sementes este valor pode chegar a $40 \%$ na base da massa (Pirie 1978).

O resultado dos teores de proteínas solúveis nas folhas serem próximos dos teores das sementes das mesmas espécies, de certa forma, tem relevância para a bioprospecção de proteínas específicas como os inibidores de proteinases, considerando a lógica da fenologia das espécies e, portanto, a disponibilidade de material biológico (folhas) em períodos constantes ao longo do ano. Adicionalmente, oito das espécies apresentam folhas permanentes, quatro as perdem parcialmente e três perdem as folhas completamente e, esta troca foliar é demarcada na Amazônia Central pela ocorrência do período seco geralmente entre os meses de agosto e setembro de cada ano. Ao contrario das etapas fenológicas de floração e frutificação e, por conseguinte, produçáo de sementes, que nem sempre acontecem com regularidade para uma dada espécie, o padráo de renovaçáo foliar das espécies arbóreas na região tropical é mais previsível.

A inibição da atividade da tripsina bovina pelos extratos foliares variou na ordem de 24 e $81 \%$ (Figura 1). Esta grande variação entre as espécies sugere a possibilidade de selecionar as mais eficazes, para melhor exploração deste potencial. 


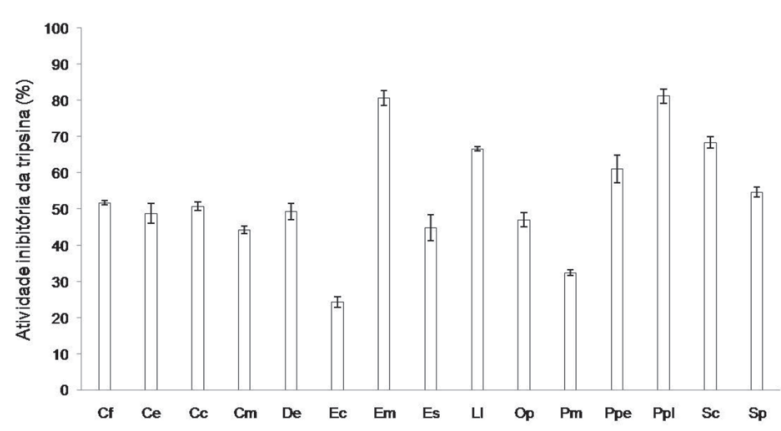

Figura 1 - Detecção da atividade inibitória da tripsina bovina em extratos foliares de 15 leguminosas arbóreas que crescem na Amazônia Central. Cf: Caesalpinia ferrea; Ce: Caesalpinia echinata; Cc: Cedrelinga cateniformis; $\mathrm{Cm}$ : Copaifera multijuga; De: Dinizia excelsa; Ec: Enterolobium contortisiliquum; Em: Enterolobium maximum; Es: Enterolobium schomburgkii; Ll: Leucaena leucocephala; 0p: Ormosia paraensis; Pm: Parkia multijuga; Ppe: Parkia pendula; Ppl: Parkia platycephala; Sc: Swartzia corrugata; Sp: Swartzia polyphylla. ( $\mathrm{n}=45$, médias seguidas de desvios padrão)

Os inibidores de tripsina presentes em folhas de $E$. maximum e P. platycephala, mostraram-se potentes inibidores desta enzima, sendo, portanto, as espécies com maiores percentuais inibitórios, de aproximadamente $80 \%$. Em contraste, E. contortisiliquum e $P$. multijuga foram as espécies com os menores valores inibitórios para tripsina, cujos percentuais foram de 24 e $32 \%$, respectivamente.

Estudos realizados com espécies de leguminosas pertencentes à flora amazônica também demonstram a presença de inibidores de tripsina nos tecidos vegetais. Nas sementes de Tachigali plumbea, Caesalpinia ferrea, Sesbania exasperata, Cedrelinga cateniformis, Swartzia polyphylla e Peltogyne venosa, os percentuais antitrípticos encontrados foram de 96; 95; 84; 69; 43 e 34\%, respectivamente (Bariani 2008; Chevreuil et al. 2009).

Apesar de estarem altamente concentrados nas sementes de leguminosas, os inibidores de proteinases também estáo presentes em outros tecidos vegetais, como em folhas de Entada africana, Senna obtusifolia e Sesbania pachycarpa, bem como em frutos de Parkia africana e Senna occidentalis, nos quais foram detectados inibidores de tripsina (Vanderjagt et al. 2000). Esses resultados demonstram a ampla distribuição dos inibidores nos diferentes tecidos vegetais e, mesmo com ampla ocorrência, possivelmente relacionada a mecanismos de defesa das plantas, a quantidade de inibidores pode variar entre espécies pertencentes ao mesmo gênero (Xavier-Filho et al. 1989) conforme ilustrado na tabela Tabela 3.

A inibição da atividade da quimotripsina bovina pelos extratos foliares também foi variável entre as espécies de leguminosas arbóreas pesquisadas, com valores entre 8 e $63 \%$ (Figura 2).
Tabela 3 - Atividade inibitória sobre a tripsina bovina em folhas, comparadas aos estudos com sementes da mesma espécie.

\begin{tabular}{lccc}
\hline \multirow{2}{*}{ Espécie } & \multicolumn{2}{c}{$\begin{array}{c}\text { Inibição da atividade da } \\
\text { tripsina bovina (\%) }\end{array}$} & \multirow{2}{*}{ Fonte } \\
\cline { 2 - 3 } & Folha & Semente & \\
\hline Cedrelinga cateniformis & 51 & 69 & Bariani 2008 \\
Caesalpinia echinata & 47 & 100 & $\begin{array}{c}\text { Oliveira et al. } \\
2002\end{array}$ \\
Caesalpinia ferrea & 54 & 95 & Bariani 2008 \\
Enterolobium & 45 & 63 & Chevreuil 2009 \\
Schomburgkii & 35 & 76 & Chevreuil 2009 \\
Parkia multijuga & 61 & 100 & Chevreuil 2009 \\
Parkia pendula & 55 & 43 & Bariani 2008 \\
\hline Swartzia polyphylla & & &
\end{tabular}

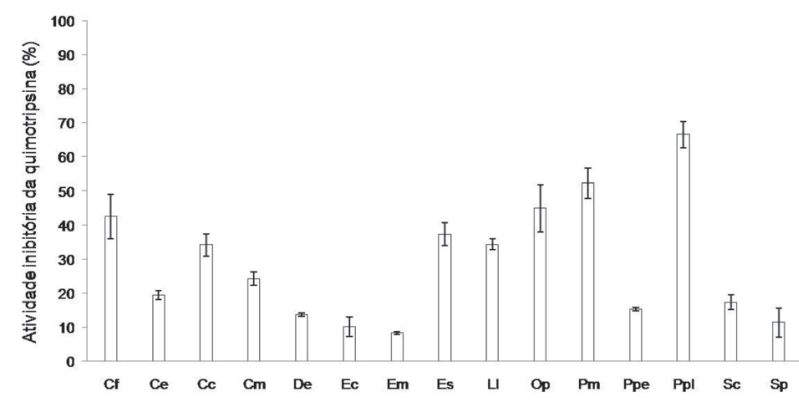

Figura 2 - Detecção da atividade inibitória da quimotripsina bovina em extratos foliares de 15 leguminosas arbóreas que crescem na Amazônia. Cf: Caesalpinia ferrea; Ce: Caesalpinia echinata; Cc: Cedrelinga cateniformis; $\mathrm{Cm}$ : Copaifera multijuga; De: Dinizia excelsa; Ec: Enterolobium contortisiliquum; Em: Enterolobium maximum; Es: Enterolobium schomburgkii; LI: Leucaena leucocephala; Op: Ormosia paraensis; Pm: Parkia multijuga; Ppe: Parkia pendula; Ppl: Parkia platycephala; Sc: Swartzia corrugata; Sp: Swartzia polyphylla. ( $n=45$, médias seguidas de desvios padrão)

As espécies com menores percentuais de inibição da quimotripsina foram E. maximum (8\%), E. contortisiliquum $(10 \%)$ e $S$. polyphylla (11\%) e, aquelas com valores maiores foram $P$. multijuga (52\%) e P. platycephala (66\%), sendo, essas duas espécies, as únicas a apresentarem atividade inibitória contra a quimotripsina acima de 50\% (Figura 2).

De modo geral, nos extratos foliares das espécies estudadas estão presentes inibidores de tripsina e quimotripsina. Contudo, as C. ferrea, C. cateniformis, E. maximum, $L$. leucocephala, $P$. pendula, P. platycephala, $S$. corrugata e $S$. polyphylla inibiram a tripsina acima de $50 \%$, enquanto a quimotripsina foi inibida, nesta faixa, apenas pelos extratos foliares de $P$. multijuga e $P$. platycephala.

Resultados similares demonstram a inibiçáo diferenciada entre as enzimas tripsina e quimotripsina, pelos inibidores presentes no extrato foliar de Terminalia arjuna, uma espécie pertencente à família Combretaceae, onde tais moléculas apresentaram maior especificidade para a tripsina (Rai et al. 2008). 
De modo geral, inibidores de proteinases vegetais apresentam variação quanto à especificidade inibitória, onde os inibidores do tipo Kunitz, por exemplo, são potentes inibidores de tripsina e pouco específicos para a quimotripsina (Garcia et al. 2004; Macedo et al. 2007).

A explicação para essa diferença na especificidade de inibição enzimática tem sido atribuída à formação do complexo estável entre enzima e inibidor, o qual é dependente da interação de aminoácidos presentes no sítio reativo do inibidor com os aminoácidos do sítio ativo da enzima, determinando interação altamente específica com suas enzimas proteolíticas alvo (Haq et al. 2004; 2005).

Desse modo, quando a posição P1 do sítio reativo for ocupada por um aminoácido lisina ou arginina, o inibidor será reconhecido pela tripsina. Porém, se o sítio reativo apresentar triptofano, fenilalanina, tirosina ou leucina, o inibidor será reconhecido pela quimotripsina. Desta forma, dependendo do tipo de resíduo de aminoácido presente no sítio reativo, existe uma enzima específica que atua sobre este inibidor (Bode e Huber 2000; Wesolowska et al. 2001; Scarafoni et al. 2008; Legowska et al. 2009).

Considerando a diferença de especificidade entre inibidores de proteinases e enzimas proteolíticas em tecidos vegetativos distintos, a prospecção de tais moléculas em folhas é importante, pois, apesar de encontrar-se em menor concentração, esse aspecto pode ser contrabalanceado pela enorme fitomassa verde e também pela própria capacidade das plantas em produzirem sementes.

Portanto, inibidores de tripsina e quimotripsina estáo presentes, diferenciadamente, nos tecidos foliares das espécies estudadas, sugerindo que outros órgãos vegetais, além das sementes, exibem potencial para aplicação em futuros ensaios envolvendo a atividade biológica de inibidores de tripsina sobre insetos, fungos e bactérias, visando prospectar biomoléculas com potencial de uso sustentável da flora Amazônica.

\section{AGRADECIMENTOS}

Os autores agradecem ao Ministério da Ciência e Tecnologia/ Instituto Nacional de Pesquisas da Amazônia e a toda a equipe do Laboratório de Fisiologia e Bioquímica Vegetal do INPA/ LFBV. Os autores desse manuscrito também são gratos ao CNPq e à FAPEAM pelas concessōes das bolsas de Iniciação Científica (IC), de pesquisa (PCI) e de produtividade (PQ) e a CAPES pelo financiamento desta pesquisa por meio do Programa de Colaboração Acadêmica (CAPES/PROCAD-2006).

\section{BIBLIOGRAFIA CITADA}

Anderson, J.M.; Ingram, J.S.I. 1993. Tropical Soil Biology and Fertility: A Handbook of Methods, second edition. CABI. 240p.

Barbosa, A.P.; Palmeira, R.C.F.; Nascimento, C.S.; Feitosa, D.S.; Cunha, M.S.C. 2006. Leguminosas Florestais da Amazônia Central I. Prospecçáo de compostos presentes na casca de espécies arbóreas. Revista Fitos, 1:47-57.

Bariani, A. 2008. Propriedades Bioquímicas e Biológicas de Proteinas de Sementes de Leguminosas Arbóreas da Amazônia. Dissertação (Mestrado: Biologia Tropical e Recursos Naturais, Instituto Nacional de Pesquisas da Amazônia), Manaus, AM. 122pp.

Bhattacharyya, A.; Mazumar, S.; Leighton, S.M.; Babu, C.R. 2006. A kunitz proteinase inhibitor from Archidendron ellipticum seeds: Purification, characterization and kinetic properties. Phytochemistry, 67: $232-241$.

Bhattacharyya, A.; Babu, C.R. 2009. Purification and biochemical characterization of a serine proteinase inhibitor from Derris trifoliata Lour. Seeds: Insight into structural and antimalarial features. Phytochemistry, 70: 703-712.

Bode, W.; Huber, R. 2000. Structural basis of the endoproteinaseprotein inhibitor interaction. Biochimica et Biophysica Acta, 1477: 241-252.

Bradford, M. M. 1976. A rapid and sensitive method for quantitation of microgram quantities of protein utilizing the principle of dye binding. Anal Biochemistry, 72: 248-254.

Brzin, J.; Popovic, T.; Ritonja, A.; Puizdar, V.; Kidric, M. 1998. Related cystatin inhibitors from leaf and from seed Phaseolus vulgaris L. Plant Science, 138: 17-26.

Chevreuil, L.R. 2009. Extração e purificação de inibidores proteoliticos em sementes de leguminosas arbóreas da Amazônia. Dissertação (Mestrado: Ciências de Floresta Tropical, Instituto Nacional de Pesquisas da Amazônia), Manaus, AM. 80p.

Chevreuil, L.R.; Gonçalves, J.F.C.; Bariani, A.; Rodrigues, J.V.F.C.; Pando, S.C. 2009. Detecção de inibidores de tripsina e atividade hemaglutinante em sementes de leguminosas arbóreas da Amazônia. Acta Amazonica, 39: 189-196.

Chye, M.L.; Sin, S.F.; Xu, Z.F.; Yeung, E.C. 2006. Serine proteinase inhibitor proteins: exogenus and endogenous functions. In Vitro Cell. Dev. Biol. - Plant, 42: 100-108.

De Leo, F.; Volpicella, M.; Licciulli, F.; Liuni, S.; Gallerani, R.; Ceci, L.R. 2002. Plant-PIs: a database for plant protease inhibitors and their genes. Nucleic Acids Research, 30: 347-348.

Erlanger, B.F.; Kolowsky, N.; Cohen, N. 1961. Preparation and properties of two new chromogenic substrates of trypsin. Archives of Biochemistry and Biophysics, 95: $271-278$.

Ezeagu, I.E.; Petzke, J.K.; Metges, C.C.; Akinsoyinu, A.O.; Ologhobo, A.D. 2002. Seed protein contents and nitrogen-toprotein conversion factors for some uncultivated tropical plant seeds. Food Chemistry, 78: 105-109. 
FAO (Food and Agriculture Organization). 1982. Food composition tables for the near East. Food and Nutrition Paper, 26. Rome: $\mathrm{FAO} / \mathrm{UN}$.

Ferreira, G.C.; Hopkins, M.J.G.; Secco, R.S. 2004. Contribuição ao conhecimento morfológico das espécies de leguminosas comercializadas no estado do Pará, como "angelim". Acta Amazonica, 34: 219 - 232.

Garcia, V.A.; Freire, M.G.M.; Novello, J.C.; Marangoni, S.; Macedo, M.L.R. 2004. Trypsin inhibitor from Poecilanthe parviflora seeds: Purification, characterization, and activity against pest proteases. The Protein Journal, 23: 343-350.

Gomes, C.E.M.; Barbosa, A.E.A.D.; Macedo, L.L.P.; Pitanga, J.C.M.; Moura, F.T.; Oliveira, A.S.; Moura, R.M.; Queiroz, A.F.S.; Macedo, F.P.; Andrade, L.B.S.; Vidal, M.S.; Sales, M.P. 2005. Effect of trypsin inhibitor from Crotalaria pallida seeds on Callosobruchus maculatus (cowpea weevil) and Ceratitis capitata (fruit fly). Plant Physiology and Biochemistry, 43: 1095-1102.

Haq, S.K.; Atif, S.M.; Khan, R.H. 2004. Protein proteinase inhibitor genes in combat against insects, pests, and pathogens: natural and engineered phytoprotection. Archives of Biochemistry and Biophysics, 431:145-159.

Haq, S.K.; Atif, S.M.; Khan, R.H. 2005. Biochemical characterization, stability studies and $\mathrm{N}$-terminal sequence of a bi-functional inhibitor from Phaseolus aureus Roxb. (Mung bean). Biochimie, 87: $1127-1136$.

Hughes, C.E. 1998. Leucaena. Manual de recursos genéticos. University of Oxford, Department of Plant Sciences, Tropical Forestry Papers, No. 37, 280p.

Legowska, A.; Debowski, D.; Lesner, A.; Wysocka, M.; Rolka, K. 2009. Introduction of non-natural amino acid residues into the substrate - specific $\mathrm{P}_{1}$ position of trypsin inhibitor SFTI-1 yields potent chymotrypsina and cathepsin $\mathrm{G}$ inhibitors. Bioorganic \& Medicinal Chemistry, 17: 3302-3307.

Lewis, G.; Schire, B.; Mackinder, B.; Lock, M. 2005. Legumes of the world. The Royal Botanic Gardens, Kew, 577pp.

Macedo, M.L.R.; Garcia, V.A.; Freire, M.G.M.; Richarson, M. 2007. Characterization of a Kunitz trypsin inhibitor with a single disulfite bridge from seeds of Inga laurina (SW.) Willd. Phytochemistry, 68: 1104-1111.

McManus, M.T.; Laing, W.A.; Watson, L.M.; Markwick, N.; Voisey, C.R.; White, D.W.R. 2005. Expression of the soybean (Kunitz) trypsin inhibitor in leaves of white clover (Trifolium repens L.). Plant Science, 168: 1211-1220.

Mello, G.C.; Oliva, M.L.V.; Sumikawa, J.T.; Machado, O.L.T.; Marangoni, S.; Novello, J.C.; Macedo, M.L.R. 2001. Purification and characterization of a new trypsin inhibitor from Dimorphandra mollis seeds. Journal of Protein Chemistry, 20: 625-632.

Mosolov, V. V.; Valueva, T. A. 2005. Proteinase Inhibitors and their function in plants: A Review. Applied Biochemistry and Microbiology, 41: 227-246.
Oliveira, L.G.; Gozzo, A.J.; Nunes, V.A.; Silva, I.C.; Sampaio, M.U.; Sampaio, C.A.M.; Araújo, M.S. 2002. Inibidores de proteases encontrados em sementes de Caesalpinia echinata (pau-brasil) - isolamento e caracterização do inibidor de tripsina. Revista Brasileira de Farmacognosia, 12: 72-74.

Pando, S.C.; Oliva, M.L.V.; Sampaio, C.A.M.; Di Ciero, L.; Novello, J.C.; Marangoni, S. 2001. Primary sequence determination of a Kunitz inhibitor isolated from Delonix regia seeds. Phytochemistry, 57: 625-631.

Pirie, N.W. 1978. Leafprotein and other aspects of fooder fractionation. Cambridge University Press, New York, NY, USA, 183pp.

Rai, S.; Aggarwal, K.K.; Babu, C.R. 2008. Isolation of a serine Kunitz trypsin inhibitor from leaves of Terminalia arjuna. Current Science, 94: 1509-1512.

Ramos, V.S.; Silva, G.S.; Freire, M.G.M.; Machado, O.L.T.; Parra, J.R.P.; Macedo, M.L.R. 2008. Purification and characterization of a trypsin inhibitor from Plathymenia foliolosa seeds. Journal of Agricultural and Food Chemistry. 56: 11348-11355.

Richardson, M. 1991. Seed storage proteins: the enzyme inhibitors. Methods in Plant Biochemistry, 5:259-305.

Scarafoni, A.; Consonni, A.; Galbusera, V.; Negri, A.; Tedeschi, G.; Rasmussen, P.; Magni, C.; Duranti, M. 2008. Identification and characterization of a Bowman-Birk inhibitor active towards trypsin but not chymotrypsin in Lupinus albus seeds. Phytochemistry, 69: 1820-1825.

Silva, M.F.; Souza, L.A.G. 2002. Levantamento das leguminosas do arquipélago das Anavilhanas, baixo Rio Negro, Amazonas. Boletim do Museu Paraense Emílio Goeldi, série Botânica, 18: $3-35$.

Torres-Castillo, J.A.; Jacobo, C.M.; Blanco-Labra, A. 2009. Characterization of a highly stable trypsin-like proteinase inhibitor from the seeds of Opuntia streptacantha (O. streptacantha Lemaire). Phytochemistry, 70: 1374-1381.

Vanderjagt, D.J.; Freiberger, C.; Vu, H.T.N.; Mounkaila, G.; Glew, R.S.; Glew, R.H. 2000. The trypsin inhibitor contento f 61 wild edible plant foods of Niger. Plant Food for Human Nutrition, 55: 335-346.

Wesolowska, O.; Krokoszynska, I.; Krowarsch, D.; Otlewski, J. 2001. Enhancement of chymotrypsin-inhibitor/ substrate interactions. Biochimica et Biophysica Acta, 1545: 78-85.

Xavier-Filho, J. 1992. The biological roles of serine and cysteine proteinase inhibitors in plant. Revista Brasileira de Fisiologia Vegetal, 4: 1-8.

Xavier-Filho, J.; Campos, F.A.P.; Ary, M.B.; Silva, C.P.; Carvalho, M.M.M.; Macedo, M.L.R.; Lemos, F.J.A.; Grant, G. 1989. Poor correlation between the levels of proteinase inhibitors found in seeds of different cultivars of cowpea (Vigna unguilata) and the resistance/ susceptibility to predation by Callosobruchus maculatus. Journal of Agricultural and Food Chemistry, 37: 1139-1143.

Recebido em 23/12/2009

Aceito em 07/07/2010 
